\title{
The Effect of Positive Affirmations on Self-Esteem and Well-Being in College Students
}

\section{Lynnelle Arquiza}

Dominican University of California

\section{Introduction}

Spontaneous other- and self-affirmation have been associated with greater levels of happiness, hopefulness, and more health benefits (Emmanuel et al., 2018).

- Past research has shown that self-esteem can be fostered through positive regard from others (Rogers, 1951 as cited by Maxwell \& Bachkirova, 2010)

- Well-being theorists believe that it is important to examine if people can intentionally enhance their resiliency by using happiness-enhancing strategies such as affirmations (Lyubomirsky \& Della Porta, 2010 as cited by Howell, 2017).

- Delivering virtual messages through a mobile phone is a widely accessible method in facilitating behavior changes through the support and immediate feedback (Sharifi et al., 2013).

\section{Method}

This study had a sample of 38 students from a small liberal arts university in the Bay Area, 23 of which completed the study (21 females and 2 males aged 18-22 years old; mainly of Asian descent).

Participants were asked to complete an online survey consisting of the three measures listed below:

1. Rosenberg Self-Esteem Scale (Rosenberg, 1965) measuring positive and negative feelings about the self using a 4-point Likert scale.

2.Flourishing Scale (Diener \& Biswas-Deiner, 2009) measuring selfperceived success in key areas of life using a 7-point Likert scale.

3. Satisfaction with Life Scale (Diener, Emmons, Larsen, \& Griffin, 1985) measuring cognitive judgments of the self-perceived life

satisfaction aspect of subjective well-being using a 7-point Likert scale.

For two weeks

participants in both conditions received affirmations twice daily between the hours of $10 \mathrm{am}$ and $10 \mathrm{pm}$, then asked to take a posttest survey.

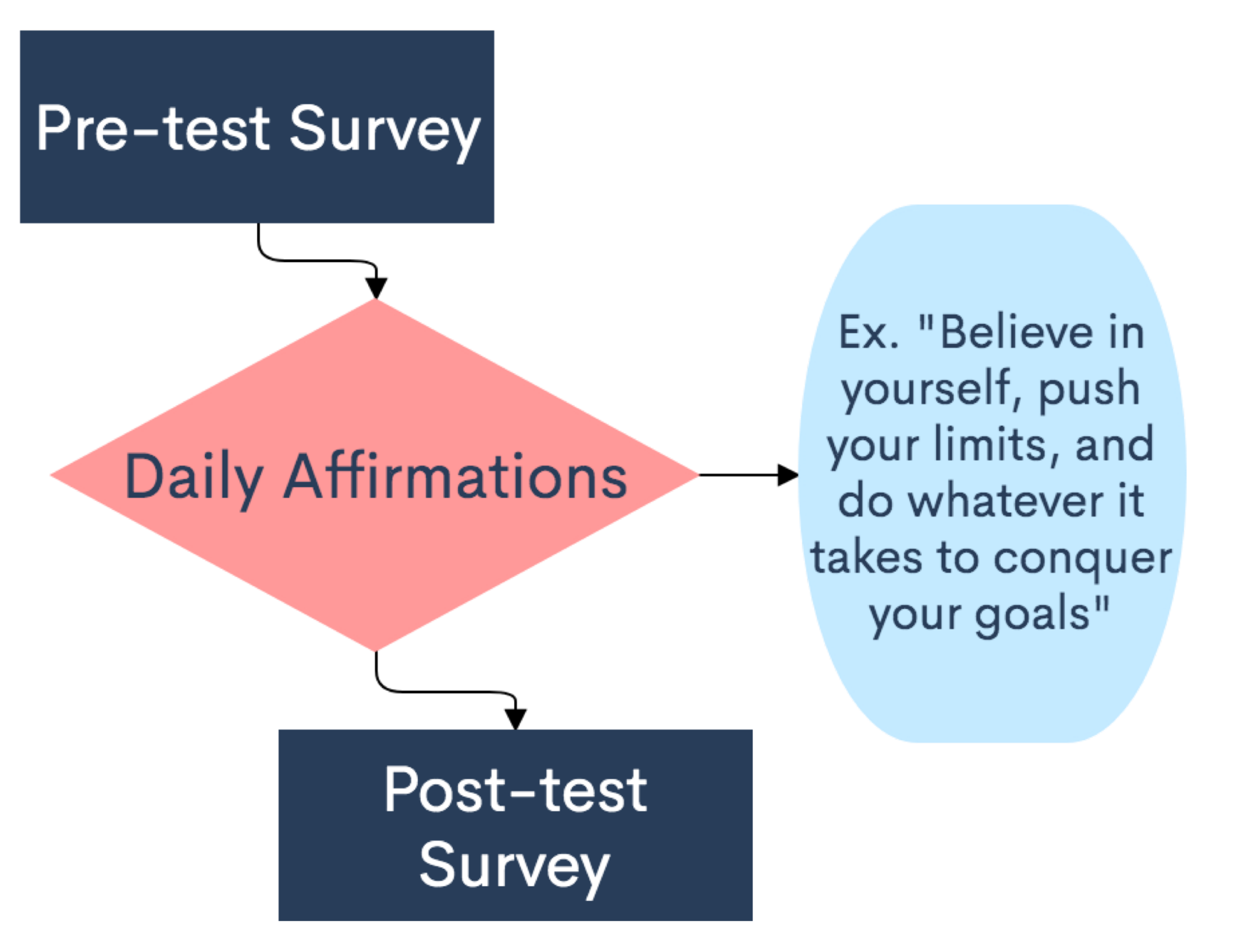

\section{Hypotheses}

Virtual affirmations will have a beneficial impact on college students' self-esteem and well-being.

Affirmations given via text message will have a greater positive impact on self-esteem and well-being than affirmations given via mobile application.

\section{Results}

When comparing pre- and post-test scores, there were significant increases in: Esteem $(t(23)=-4.447, p<0.001)$, Flourishing $(t(23)=-3.574, p<0.005)$, and SWLS $(t(23)=-3.759, p<t$ $0.005)$.

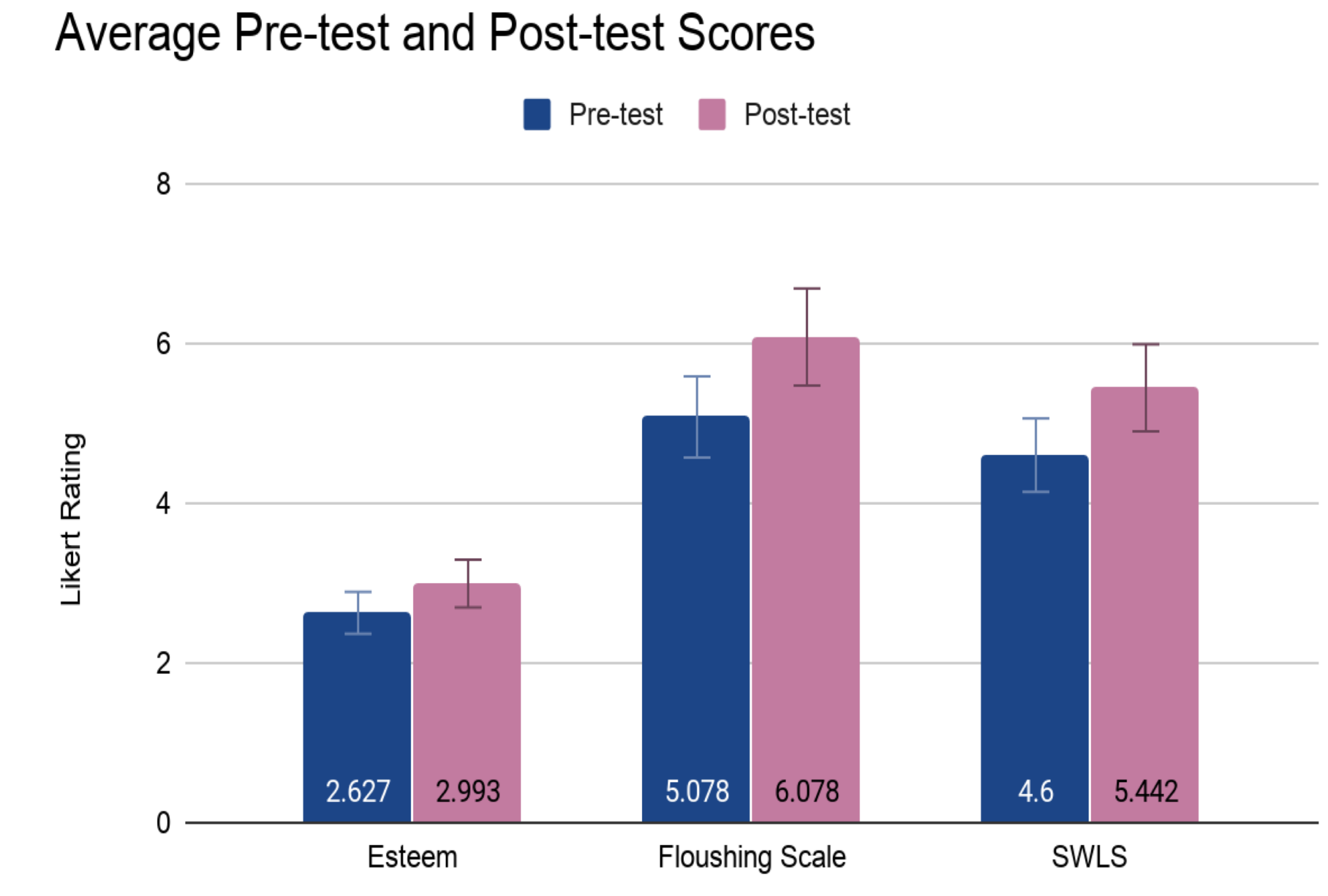

When comparing score changes for each condition, there were no significant changes in: Esteem $(t(22)=-1.511, p>$ $0.05)$, Flourishing $(t(22)=0.723, p>0.05)$, and SWLS $(t(22)=0.674, p>0.05)$.

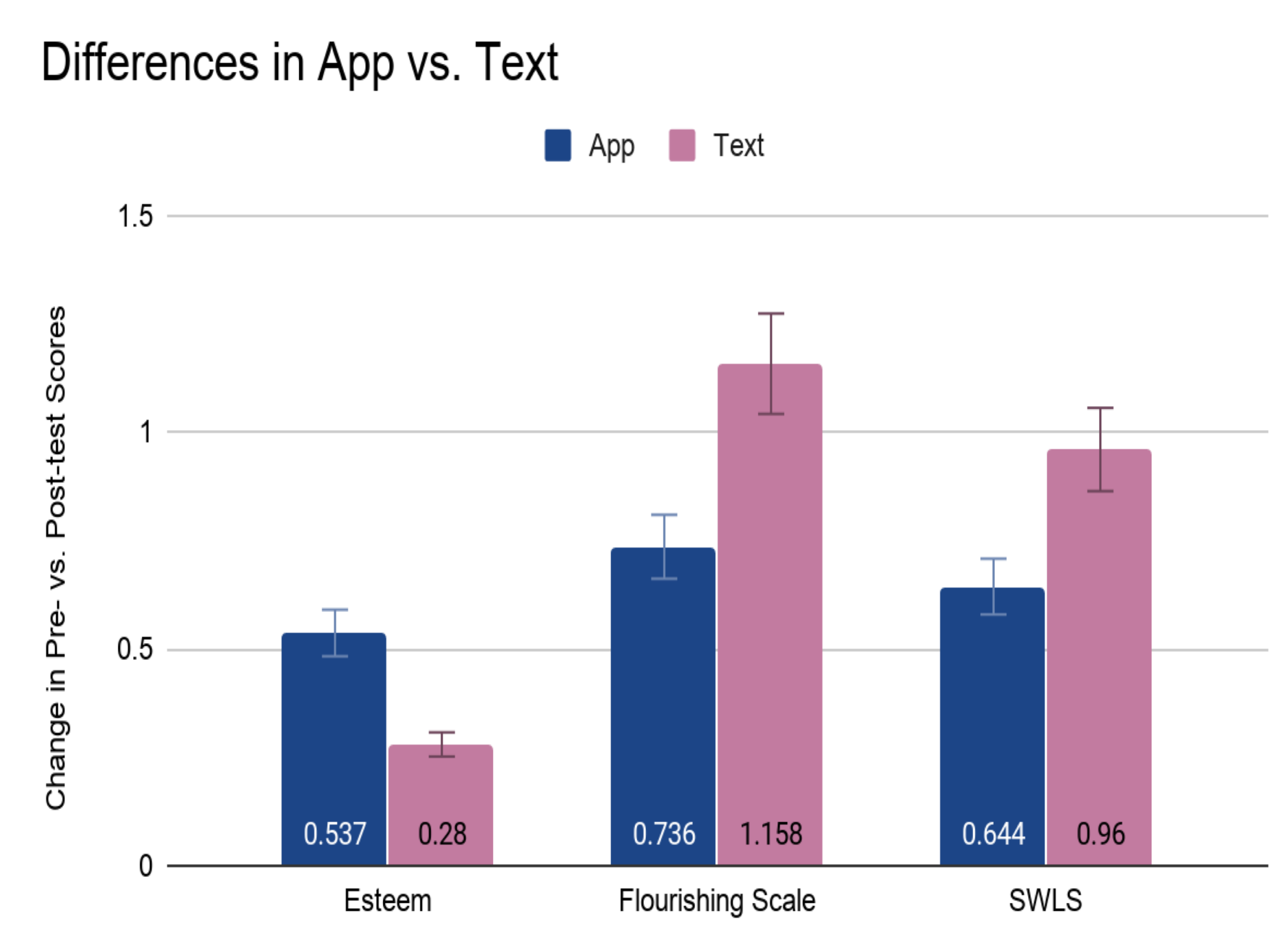

\section{Conclusions}

\section{Key findings}

- Significant increases were found between pre-test and post-test scores for self-esteem, flourishing, and satisfaction with life.

- No significant differences were found between changes in scores of the text and mobile app conditions.

- One variable had greater change in one condition, while the other two had greater change in the other condition

Future directions

- Replicate this study with a different population

- Follow up after 4-6 weeks to see if these benefits last beyond the intervention

Implications

- Virtual positive affirmations have a statistically significant beneficial impact on reported self-esteem and well-being

- There are simple things people can do to better the lives of others

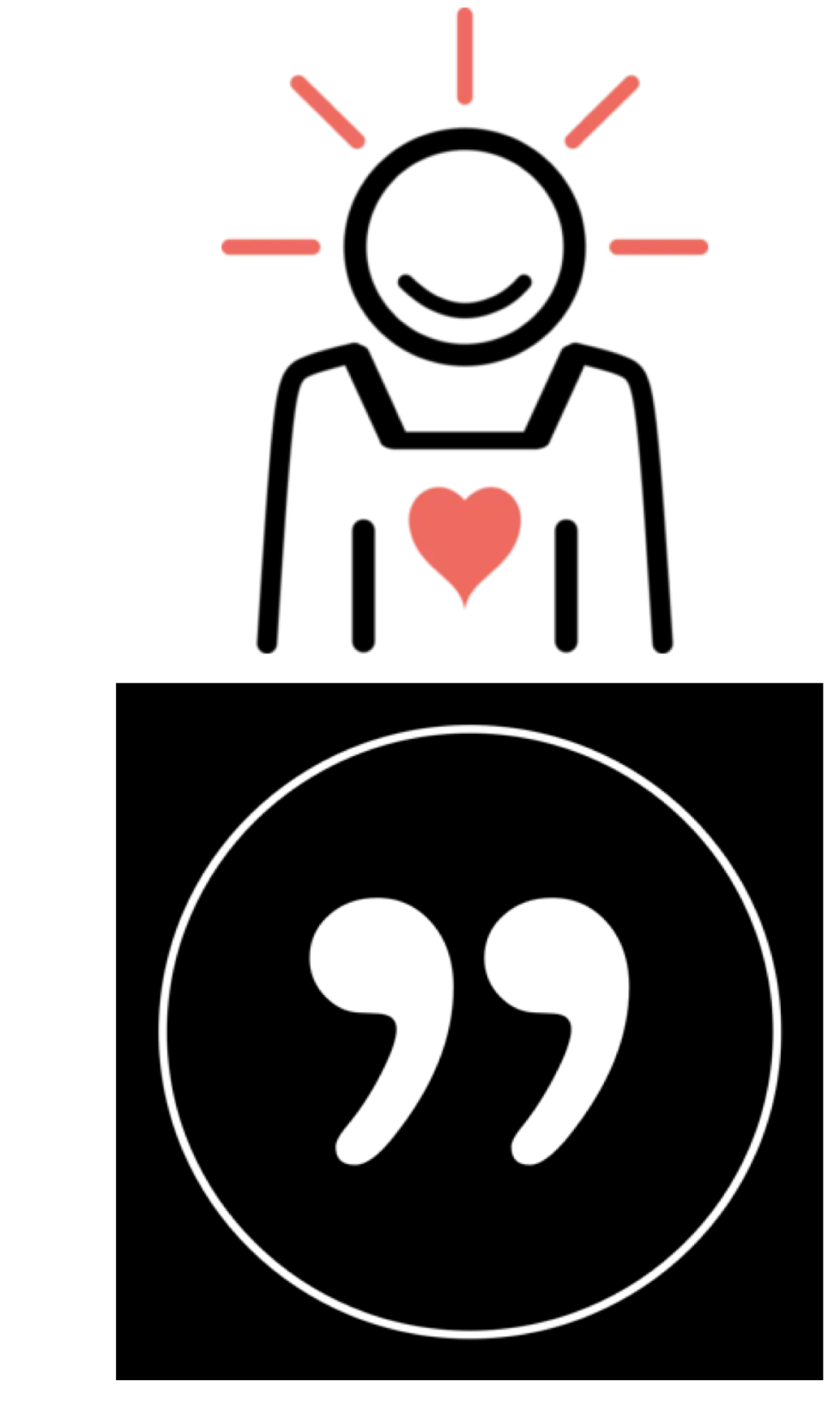

